\title{
Advanced interatrial block may be a useful parameter for determining a clinically relevant subgroup of heart failure patients with preserved ejection fraction - a pilot study
}

\section{Filip Lončarić*, Dora Fabijanović, Vedran Velagić, Nina Jakuš, Marijan Pašalić, Olvo Planinc, Davor Miličić, Maja Čikeš}

University of Zagreb School of Medicine, University Hospital Centre Zagreb, Zagreb, Croatia
RECEIVED:

September 24, 2017

ACCEPTED:

September 26, 2017

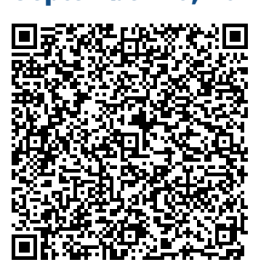

KEYWORDS: advanced interatrial block, heart failure, heart failure with preserved ejection fraction, $\mathrm{P}$ wave morphology, surface electrocardiogram.

CITATION: Cardiol Croat. 2017;12(9-10):357-358. | https://doi.org/10.15836/ccar2017.357

*ADDRESS FOR CORRESPONDENCE: Filip Lončarić, Klinički bolnički centar Zagreb, Kišpatićeva 12, HR-10000 Zagreb, Croatia. / Phone: +385-91-2220-480 / E-mail: Ioncaric.filip@gmail.com

ORCID: Filip Lončarić, http://orcid.org/0000-0002-7865-1108 • Dora Fabijanović, http://orcid.org/0000-0003-2633-3439 Vedran Velagić, http://orcid.org/0000-0001-5425-5840 • Nina Jakuš, http://orcid.org/0000-0002-9346-6402 Marijan Pašalić, http://orcid.org/0000-0002-3197-2190 • Ivo Planinc, http://orcid.org/0000-0003-0561-6704 Davor Miličić, http://orcid.org/0000-0001-9101-1570 • Maja Čikeš, http://orcid.org/0000-0002-4772-5549

IIIIIIIIIIIIIIIIIIIIIIIIIIIIIIIIIIIIIIIIIIIIIIIIIIIIIIIIIIIIIIIIIIIIIIIIIIIIIIIIIIIIIIIIIIIIIIIIIIIIIIIIIIIIIIIIIIIIIIIII

Background: An advanced interatrial block (aIAB) is seen on the ECG as the combination of a P wave duration $>120 \mathrm{~ms}$ and biphasic $\mathrm{P}$ wave morphology in the inferior leads. It is considered a marker of an electromechanically dysfunctional left atrium (LA) and hence a risk factor for supraventricular arrhythmias and heart failure (HF). ${ }^{1}$ The aim of our pilot study is to explore aIAB as a potential marker for determining a clinically relevant subgroup of HF patients.

Patients and Methods: An echocardiogram and a surface ECG were performed on a total of $51 \mathrm{HF}$ patients in sinus rhythm (31 (61\%) with HF with preserved ejection fraction (HFpEF), 20 (39\%) with HF with reduced ejection fraction (HFrEF)) diagnosed per the current guidelines, and 20 sex-matched healthy controls. Echocardiographic parameters of LA structure and function were measured. ECG measurements were performed digitally with an electronic calliper.

Results: Prevalence of aIAB was $11 \%(\mathrm{n}=8)$ in the studied group, significantly greater in HFpEF patients, compared to HFrEF patients and healthy controls (88\% vs. $0 \%$ vs. $12 \%, p=0.025$, Figure 1 ). The HFpEF patients formed an aIAB HFpEF subgroup ( $\mathrm{n}=7$ ) that was compared to two control groups, both without P wave duration $>120$ ms or biphasic $P$ wave morphology in the inferior leads: age- and sex- matched HFpEF patients $(n=7)$ and sex-matched healthy controls $(n=12)$. Based on this subanalysis, the aIAB patients had a significantly higher occurrence of paroxysmal atrial fibrillation (healthy controls vs. HFpEF controls vs. aIAB: $0 \%$ vs. $43 \%$ vs. $86 \%, p<0.0001$, Table 1 ). This subgroup also had the largest LA volumes $(26.6(18.7,29.6)$

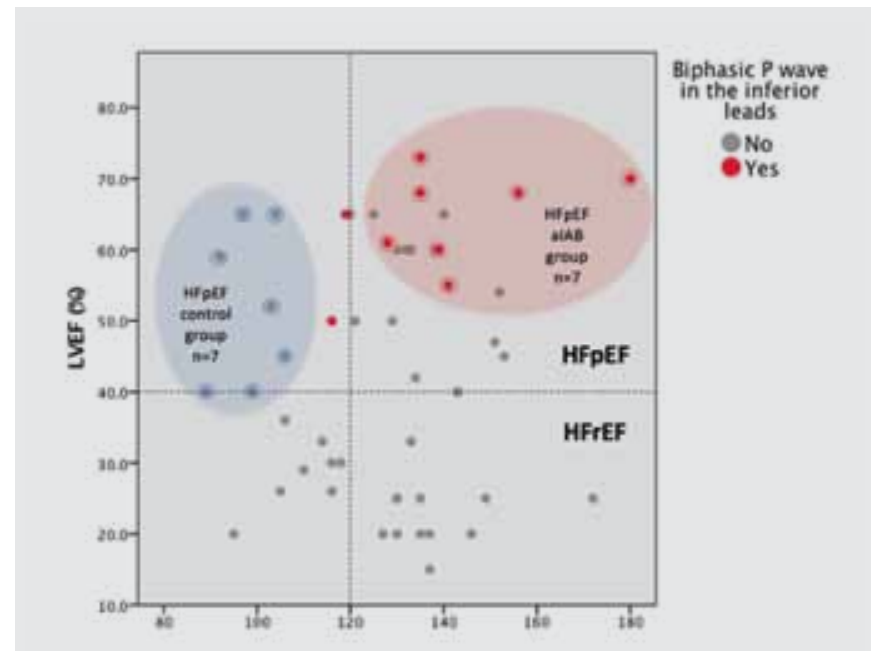

FIGURE 1. Selection of the heart failure subgroups based on left ventricular ejection fraction, $P$ wave duration and biphasic $P$ waves in the inferior leads $(n=51)$.

50.6) $\mathrm{ml} / \mathrm{m} 2$, healthy controls vs. HFpEF controls vs. aIAB, respectively, $\mathrm{p}<0.0001$, Table 1 ) and lowest LA ejection fraction $(57.8(46.4,66.7)$ \% vs. $39.7(31.0,41.3) \%$ vs. $34.6(31.8,44.6) \%$, healthy controls vs. HFpEF controls vs. aIAB, respectively, $\mathrm{p}=0.004$, Table 1 )

Conclusion: This pilot study relates aIAB to the HFpEF part of the HF spectrum. Significant differences in LA structural and functional characteristics suggest that aIAB may be a useful parameter for determining a clinically relevant subgroup of HFpEF patients, however an analysis of a larger patient cohort would be required to further establish these findings. 
TABLE 1. Baseline clinical and echocardiographic characterises of the studied patient subgroups.

\begin{tabular}{|c|c|c|c|c|c|c|}
\hline & \multicolumn{3}{|c|}{ Biphasic $P$ wave in inferior leads and $P$ wave $>120 \mathrm{~ms}$} & \multicolumn{3}{|c|}{$P$ values } \\
\hline & \multirow{2}{*}{$\begin{array}{c}\text { Yes } \\
\text { alAB }\end{array}$} & \multicolumn{2}{|c|}{ No } & \multirow{2}{*}{$\begin{array}{c}\text { alAB } \\
\text { vs }\end{array}$} & \multirow{2}{*}{$\begin{array}{c}\text { alAB } \\
\text { vs }\end{array}$} & \multirow{2}{*}{$\begin{array}{c}\begin{array}{l}\text { HFpEF } \\
\text { controls }\end{array} \\
\text { vs }\end{array}$} \\
\hline & & HFpEF controls & Healthy controls & & & \\
\hline & $(n=7)$ & $(n=7)$ & $(n=12)$ & $\begin{array}{l}\text { HFpEF } \\
\text { controls }\end{array}$ & $\begin{array}{l}\text { Healthy } \\
\text { controls }\end{array}$ & $\begin{array}{l}\text { Healthy } \\
\text { controls }\end{array}$ \\
\hline Male sex - no. (\%) & $1(14)$ & $1(14)$ & $4(33)$ & 1 & 0.603 & 0.603 \\
\hline Age (IQR) -years & $74(71-81)$ & $75(67-82)$ & $54(51-55)$ & 1 & $<0.0001$ & 0.010 \\
\hline Paroxysmal AF - no. (\%) & $6(86)$ & $3(43)$ & $0(0)$ & 0.266 & $<0.0001$ & 0.036 \\
\hline LVEF (IQR) - \% & $68(60-70)$ & $52(40-65)$ & $60(52-64)$ & 0.026 & 0.100 & 0.351 \\
\hline LAVI (IQR) - $\mathrm{ml} / \mathrm{m}^{2}$ & $46.4(41.4-50.6)$ & $37.6(32.7-54.1)$ & $26.6(18.7-29.6)$ & 0.318 & $<0.0001$ & 0.001 \\
\hline LAA (IQR) - $\mathrm{cm}^{2}$ & $26.8(23.9-32.0)$ & $21.6(21.0-25.5)$ & $18.2(15.0-20.3)$ & 0.073 & $<0.0001$ & 0.007 \\
\hline LAEF (IQR) - \% & $34.6(31.8-44.6)$ & $39.7(31.0-41.3)$ & $57.8(46.4-66.7)$ & 0.902 & 0.013 & 0.005 \\
\hline$V \max ($ IQR) - ml & $85.0(81.0-109.0)$ & $71.0(61.0-92.0)$ & $51.5(35.5-59.5)$ & 0.259 & $<0.0001$ & 0.005 \\
\hline V min (IQR) - ml & $53.0(35.0-75.0)$ & $42.0(38.0-51.0)$ & $20.5(12.3-28.8)$ & 0.456 & 0.001 & 0.0001 \\
\hline preA volume (IQR) - ml & $64.0(52.0-86.0)$ & $59.0(46.0-65.0)$ & $38.0(22.2-28.8)$ & 0.456 & $<0.0001$ & 0.010 \\
\hline
\end{tabular}

\section{LITERATURE IIIIIIIIIIIIIIIIIIIIIIIIIIIIIIIIIIIIIIIIIIIIIIIIIIIIIIIIIIIIIIIIIIIIIIIIIIIIIIIIIIIIIIIIIIIIIIIIIIIIIII}

1. Bayés de Luna A, Platonov P, Cosio FG, Cygankiewicz I, Pastore C, Baranowski R, et al. Interatrial blocks. A separate entity from left atrial enlargement: a consensus report. J Electrocardiol. 2012 Sep;45(5):445-51. https://doi.org/10.1016/j.jelectrocard.2012.06.029 